\title{
Regulation of sister chromatid cohesion during the mitotic cell cycle
}

\author{
ZHENG Ge \& YU HongTao* \\ Howard Hughes Medical Institute, Department of Pharmacology, University of Texas Southwestern Medical Center, Dallas TX 75390, USA
}

Received September 3, 2015; accepted October 16, 2015; published online October 27, 2015

\begin{abstract}
Orderly execution of two critical events during the cell cycle-DNA replication and chromosome segregation-ensures the stable transmission of genetic materials. The cohesin complex physically connects sister chromatids during DNA replication in a process termed sister chromatid cohesion. Timely establishment and dissolution of sister chromatid cohesion is a prerequisite for accurate chromosome segregation, and is tight regulated by the cell cycle machinery and cohesin-associated proteins. In this review, we discuss recent progress in the molecular understanding of sister chromatid cohesion during the mitotic cell cycle.
\end{abstract}

cell cycle, mitosis, sister chromatid cohesion, cohesin, cohesin loading, cohesin release, DNA replication, cohesion establishment

Citation: Zheng G, Yu HT. Regulation of sister chromatid cohesion during the mitotic cell cycle. Sci China Life Sci, 2015, 58: 1089-1098, doi: $10.1007 / \mathrm{s} 11427-015-4956-7$

During the cell cycle, DNA undergoes replication during S phase to generate two identical copies of each chromosome, called sister chromatids. During mitosis, sister chromatids are separated and partitioned evenly to the two daughter cells to maintain genomic stability. Cells receive too many or too few chromosomes become aneuploid. Aneuploidy can drive tumorigenesis in a context-dependent manner $[1,2]$. To prevent premature sister chromatid separation and ensure accurate chromosome segregation, sister chromatids are physically tethered to each other through the process of sister chromatid cohesion, as well as DNA catenation, from $\mathrm{S}$ phase till metaphase. Sister chromatid cohesion is mediated by the highly conserved ring-shaped cohesin complex, which topologically entraps chromosomes $[3,4]$.

Cohesion establishment, maintenance, and removal at different cell cycle phases require a series of coordinated interactions between cohesin and its regulators (Figure 1). Cohesin is loaded onto DNA by the cohesin loader complex

*Corresponding author (email: Hongtao.Yu@utsouthwestern.edu)
Scc2-Scc4 in telophase and early G1 [5-7]. At this stage, the chromatin-bound cohesin is highly dynamic, and can be released from chromosomes by the cohesin releasing factor Wapl, with the help of the scaffold protein Pds5 [8-11]. During $\mathrm{S}$ phase, the replicated sister chromatids are tethered by cohesin to establish sister chromatid cohesion. Cohesion establishment requires the acetylation of two adjacent, evolutionarily conserved lysines on Smc3 by the acetyltransferase Eco1 (Esco1/2 in vertebrates) [12-17], and in metazoans, the subsequent recruitment of sororin to cohesin through Pds5 [18-21]. Smc3 acetylation and sororin antagonize the cohesin-releasing activity of Wapl-Pds5, thereby stabilizing cohesin on chromosomes [17,21]. Finally, in mitosis, cohesin is released from chromosomes in a stepwise manner in vertebrates [22]. In early mitosis, Pds5-bound sororin is phosphorylated by mitotic kinases and dissociates from cohesin [21,23-25]. Sororin dissociation allows Wapl to gain access to Pds5 and cohesin, releasing cohesin from chromosome arms. At centromeres, 


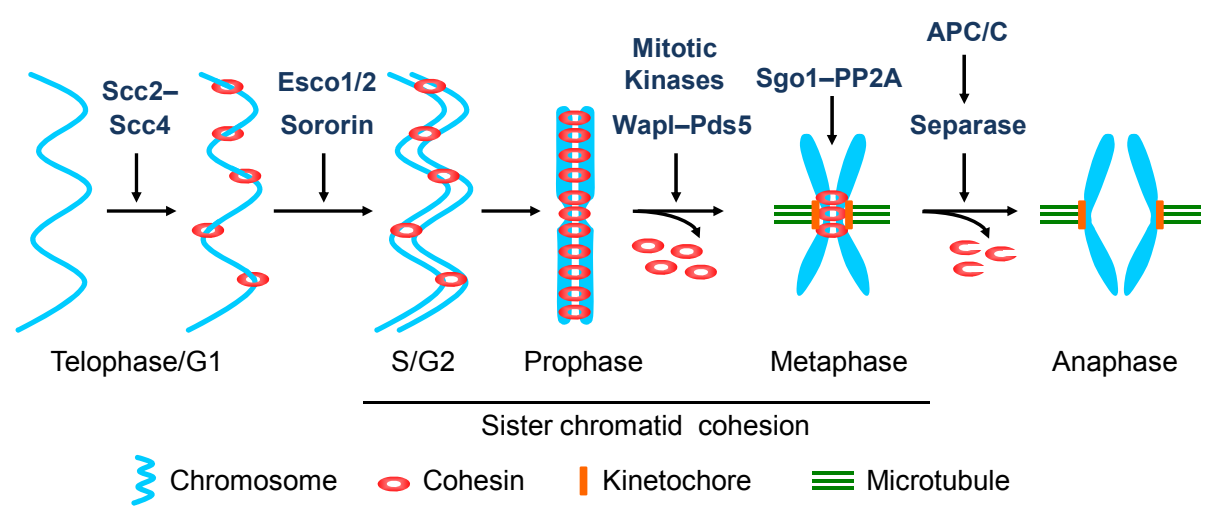

Figure 1 The cohesin cycle in human cells. The Scc2-Scc4 complex promotes cohesin loading onto chromosomes in telophase and early G1. During DNA replication in S phase, Esco1/2 and sororin are required to stabilize cohesin on chromosomes and help to establish sister chromatid cohesion. In prophase, cohesin on chromosome arms are released by mitotic kinases and the Wapl-Pds5 complex, whereas cohesin at centromeres is protected by Sgo1-PP2A until the metaphase-anaphase transition. After kinetochores attach to microtubules from opposite spindle poles and the spindle checkpoint is silenced, active separase cleaves centromeric cohesin and enables sister chromatid separation in anaphase.

however, a pool of cohesin is shielded from Wapl by the Sgo1-PP2A complex through multiple mechanisms [26-32]. After all sister kinetochores properly attach to microtubules from the opposite spindle poles, Sgo1 redistributes from centromeres to kinetochores [33,34], leaving centromeric cohesin unprotected. The unprotected cohesin is cleaved and removed by the protease separase, which becomes active when its inhibitory chaperone securin and cyclin B1 are degraded at the metaphase-anaphase transition $[35,36]$. The two separated sets of sister chromatids are equally partitioned to produce two genetically identical daughter cells.

In addition to sister chromatid cohesion, cohesin performs critical functions in other fundamental chromatin-based processes, including transcription, chromatin compaction, and DNA repair [37,38]. Mutations in cohesin and its regulators lead to human diseases termed cohesinopathies, which are characterized by a wide range of developmental defects, including growth defects, mental retardation, facial anomalies, and other systemic abnormalities [6,39-41]. The pathogenesis of such developmental diseases has been linked to the altered functions of cohesin in transcription regulation during embryogenesis.

In this review, we discuss the recent discoveries about the structure and function of cohesin and its associated regulators. Many of the same proteins or their close homologs also regulate sister chromatid cohesion during meiosis [42]. Here, we mainly focus on the regulation of sister chromatid cohesion during the mitotic cell cycle.

\section{Architecture of the cohesin core complex}

Originally discovered through genetic screens in yeast $[43,44]$, cohesin components were later found to be highly conserved in all eukaryotes [45-47]. In human so- matic cells, the cohesin complex consists of four core subunits: Smc1, Smc3, Scc1, and either SA1 or SA2. Smc1 and Smc3 are ATPases related to ABC transporters, and belong to the structural maintenance of chromosomes (Smc) protein family. The ATPase domain of Smc1 or Smc3 is split into two halves by a long coiled coil domain (Figure 2). A hinge domain is located at the middle of the coiled coil. The coiled coil folds back intramolecularly, allowing the two ATPase halves to form a single globular ATPase head. The hinge domains of Smc1 and Smc3 mediate their heterodimerization. All members in the Smc protein family contribute to the maintenance of genome integrity. In addition to the Smc1-Smc3 heterodimer in cohesin, the Smc2-Smc4 heterodimer is a part of the condensin complex that mediates chromosome condensation while the Smc5-Smc6 complex has multiple functions in DNA damage repair $[38,48]$.

The ATPase heads of Smc1 and Smc3 are connected by sister chromatid cohesion protein 1 (Scc1), a member of the kleisin protein family, forming a tripartite ring. Recent structural and biochemical studies have revealed that this Smc1-Smc3-Scc1 tripartite ring is asymmetric (Figure 2) $[49,50]$. The $\mathrm{C}$-terminal region of $\mathrm{Scc} 1$ had been shown previously to form a winged-helix domain (WHD) that interacts directly with the Smc1 ATPase head [51]. By contrast, the N-terminal region of Scc1 folds into two helices, which form a four-helix bundle with the coiled-coil region adjacent to the Smc3 ATPase head [49].

The central region of Scc1 associates with either SA1 or SA2 in vertebrates, two homologues of yeast Scc3. Recently, the crystal structures of human SA2 bound to the central region of $\mathrm{Scc} 1$ and free yeast $\mathrm{Scc} 3$ were determined [32,52]. These structures showed that SA2/Scc3 is a HEAT repeat-containing protein shaped like a dragon (Figure 2). The central region of Scc1 folds into several short helices and binds to SA2 through an extensive binding in- 


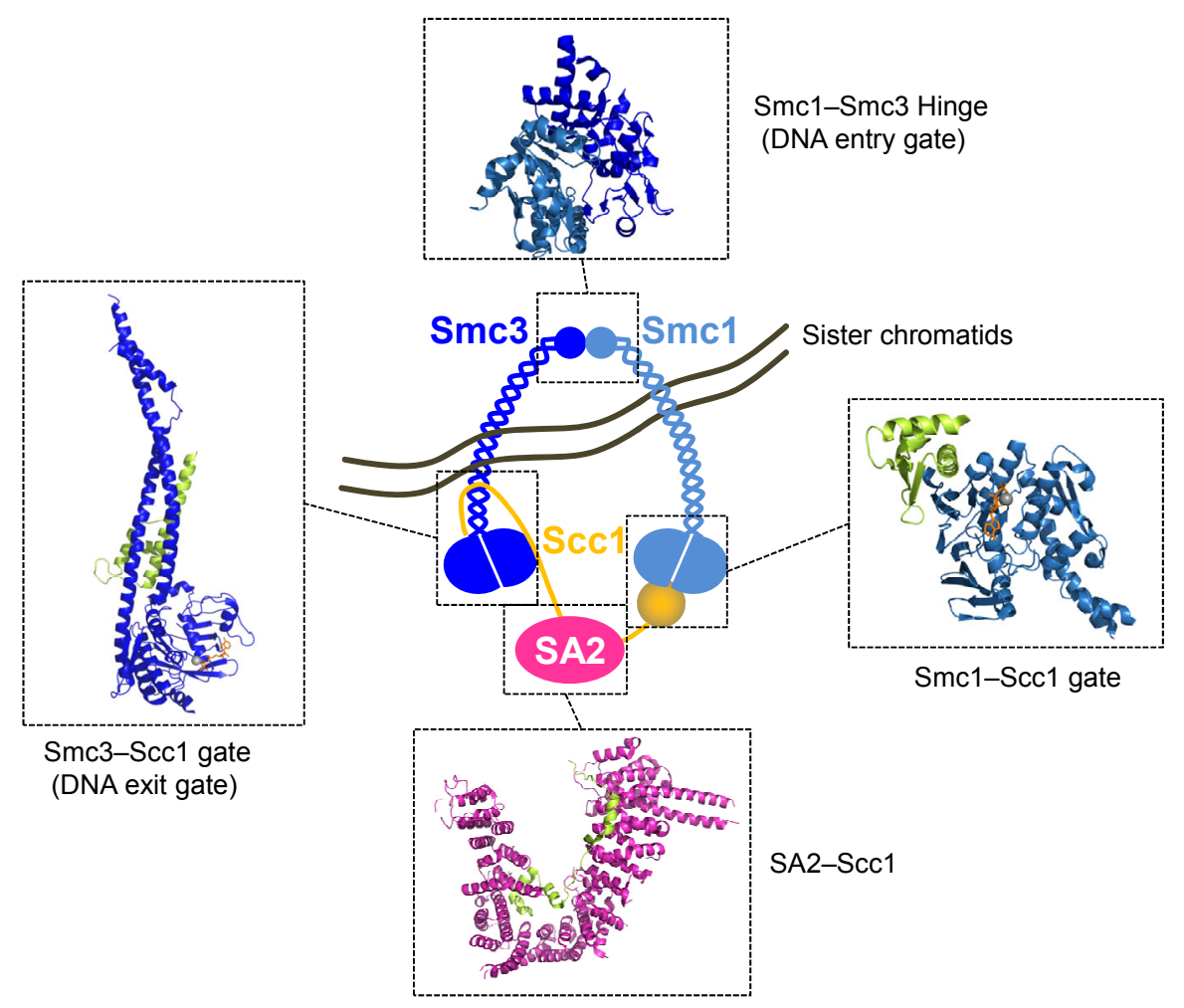

Figure 2 The architecture of the cohesin complex. Smc1, Smc3, Scc1, and SA1 or SA2 are core subunits of cohesin in human cells. They form a ring-shaped structure to topologically entrap sister chromatids. Crystal structures of all three potential gates of the cohesin ring (from different species) and the structure of SA2 bound to the central region of Scc1 have been determined, and are shown in ribbon diagrams.

terface, with many residues at the interface being highly conserved [32]. In addition to strengthening the tripartite ring of cohesin, SA2 serves as a binding platform for multiple cohesin regulators, including Wapl and Sgol.

Cohesin can topologically entrap DNA inside its ring structure [53,54]. Both the loading of cohesin onto DNA and its release from DNA thus require the opening of the ring. There are three possible gates in the entire ring: the Smc1-Smc3 hinge, the Smc1-Scc1 gate, and the Smc3-Scc1 gate (Figure 2). The crystal structures of all three gates have been determined. Evidence in both yeast and human cells suggests that cohesin loading onto chromatin involves the opening of the Smc1-Smc3 hinge [55,56]. Thus, the Smc1-Smc3 hinge has been proposed to be the DNA entry gate of cohesin.

Several lines of recent evidence suggest that the Smc3-Scc1 gate is the DNA exit gate of cohesin. In yeast, fusion of Smc3 to the N-terminal region of Scc1 protects cohesin from its releasing activity in interphase [11]. In human cells, artificially tethering Smc3 to Scc1 results in persisting cohesin on chromosome arms in prophase and prometaphase [56], suggesting that the Smc3-Scc1 fusion blocks the action of Wapl-dependent cohesin release in the prophase pathway. Furthermore, mutations that destabilize the Smc3-Scc1 interface abolish the stable interaction between cohesin and chromatin, and disrupt sister chromatid cohesion in human cells [50]. Therefore, the Smc3-Scc1 interface is likely the conserved DNA exit gate of cohesin. Why DNA enters and exits cohesin through two different gates remains a mystery.

\section{Cohesin-associated regulators}

Being the core subunits of the cohesin complex, Smc1, Smc3, Scc1, and SA1/2 are essential for sister chromatid cohesion. Apart from the four core subunits, several additional proteins are identified as cohesin-associated regulators that interact with cohesin transiently and often in a cell cycle-regulated manner. These regulators include Pds5, Wapl, Sgo1, and in metazoans, sororin, many of which interact with the Scc1-SA1/2 heterodimer in cohesin. These regulatory proteins determine the mode and dynamics of cohesin association with chromosomes.

The precocious dissociation of sisters protein 5 (Pds5) is a highly conserved, large HEAT repeat-containing protein $[57,58]$. In vertebrates, there are two Pds5 homologues, Pds5A and Pds5B [59]. Pds5 performs both positive and negative functions in sister chromatid cohesion in multiple organisms, possibly through recruiting both positive regulators (such as Eco1 and sororin) and negative regulators (such as Wapl) to cohesin. In the budding yeast, Pds5 is 
essential for cell viability and for cohesion establishment and maintenance $[57,58,60]$. In both budding and fission yeast, Pds5 also interacts with Wapl to mediate cohesin release from chromosomes, and as such, suppressor mutations in Pds5 bypass the requirement for Eco1-mediated Smc3 acetylation during cohesion establishment [10,17,61]. In Xenopus egg extracts, Pds5 collaborates with Wapl to facilitate the release of cohesin from chromatin and promotes sister chromatid resolution during early mitosis [62]. Pds5A- and Pds5B-deficient mice have developmental abnormalities $[63,64]$, and both Pds5A and Pds5B are shown to contribute to sister chromatid cohesion in mouse cells [63]. In human cells, Pds5 is required for Smc3 acetylation [65], suggesting that it should be required for cohesion establishment. However, only mild or no cohesion defects were observed in Pds5A and Pds5B-depleted human cells $[59,65]$, possibly due to incomplete depletion and the dual roles of Pds5 in both cohesion establishment and resolution. Further studies, such as in vitro biochemical reconstitution and structural analysis, are required to more clearly define the functions of Pds5 in sister chromatid cohesion.

The wings apart-like protein (Wapl) protein was initially identified as an important regulator of heterochromatin organization and chromosome segregation in Drosophila [66], and was subsequently shown to be conserved from yeast to man, with high homology in the C-terminal domain [8]. Crystal structures of human and fungal Wapl proteins reveal that the C-terminal domain of Wapl consists of HEAT repeats, which form functionally important surfaces for cohesin binding $[67,68]$. The N-terminal region of Wapl appears to be flexible and provides additional interactions with both cohesin and Pds5 [68]. Wapl is a key negative regulator of cohesin, and promotes cohesin release from chromatin, presumably through opening the DNA exit gate at the Smc3-Scc1 interface [50]. In all organisms, Wapl inactivation largely bypasses the requirement for positive cohesion factors, including Eco1, sororin, and Sgo1 [8,9,17,21]. In interphase cells, Wapl is associated with cohesin through the scaffold protein Pds5, and mediates the dynamic association of cohesin with chromatin $[8,11]$. Ablation of Wapl in mouse cells leads to the clustering of cohesin and causes improper chromatin compaction that impedes transcription [69]. In early mitosis, Wapl triggers cohesin release from chromosome arms. This activity of Wapl promotes sister chromatid decatenation, spares cohesin from further cleavage by separase, and preserves intact cohesin for the next cell cycle $[69,70]$.

Sororin was initially discovered as a substrate of the anaphase-promoting complex or cyclosome (APC/C), a multi-subunit ubiquitin ligase complex [18]. As a positive regulator of cohesin, sororin is required for the establishment and maintenance of sister chromatid cohesion [18,19]. During DNA replication, sororin is recruited to cohesin through Pds5 in a process that requires Smc3 acetylation, and antagonizes the function of Wapl to stabilize cohesin on chromosomes [21]. So far, sororin homologues have only been found in metazoans, not in yeast. The Nterminal flexible region of Wapl proteins in metazoans is much longer than that in yeast, and is known to interact with Pds5 [11,50,68]. It is possible that sororin competes with metazoan-specific N-terminal elements of Wapl for binding to Pds5. The co-emergence of sororin and the longer $\mathrm{N}$ terminal region of Wapl during evolution might offer an additional layer of regulation in sister chromatid cohesion in higher eukaryotes.

\section{Cohesin loading onto DNA}

Cohesin is loaded onto DNA soon after chromosome segregation and prior to DNA replication. This process is mediated by the cohesin loading complex Scc2-Scc4 [5-7]. Mutations in Scc2 (also known as NIPBL) in humans cause a severe developmental disorder called Cornelia de Lange Syndrome (CdLS), which is a form of cohesinopathy [6,71]. Scc2 is a large protein that is predicted to have an unstructured N-terminal region and a C-terminal domain consisting of HEAT repeats [72]. Recently, two research groups determined the crystal structure of yeast Scc4 bound to the N-terminal region of Scc2 [73,74]. The TPR repeats of Scc4 adopts a barrel shape and encapsulates the N-terminal region of Scc2 inside the barrel, thus protecting this flexible region of Scc2.

Using purified fission yeast cohesin and the Scc2-Scc4 loader complex, Murayama and Uhlmann reconstituted topological cohesin loading onto DNA in vitro [75]. They showed that cohesin loading required ATP hydrolysis, and that Scc2 stimulated the ATPase activity of Smc1-Smc3. As mentioned above, the Smc1-Smc3 hinge is the proposed DNA entry gate and has to be opened during cohesin loading by Scc2-Scc4. The ATPase heads of Smc1 and Smc3 are located at the opposite end of the ring structure (Figure 2). An interesting question is how ATP hydrolysis at one end of the ring opens the hinge region at the other end.

In addition to simply depositing cohesin onto DNA, the Scc2-Scc4 complex ensures that cohesin is loaded at the proper chromosomal location. In mammalian cells, Scc2 (NIPBL) has been shown to form a complex with cohesin and the mediator complex to load cohesin at gene promoters [76]. In budding yeast, the chromatin-remodeling complex at promoters of actively transcribing genes recruits the Scc2-Scc4 complex to the nucleosome-free regions, which loads cohesin to maintain proper DNA morphology in these regions [77]. Furthermore, a conserved patch on the surface of yeast Scc4 is critical for the recruitment of the Scc2-Scc4 complex to centromeres to build cohesion [73], although the centromere receptor of Scc4 has not been identified. In Xenopus egg extracts, the pre-replication complex (pre-RC) and the Cdc7-Drf1 kinase (DDK) recruit Scc2-Scc4 to origins of replication to promote cohesin 
loading [78-80].

Instead of staying at sites where they are originally loaded by the loader complex, cohesin rings are ultimately positioned to sites of convergent transcription in yeast and at CCCTC-binding factor (CTCF) sites in mammalian cells [81-84]. CTCF recognizes DNA sequences containing CCCTC repeats with its zinc finger domains, and plays important roles in the regulation of chromatin architecture and gene transcription [84]. CTCF has been proposed to cooperate with cohesin to induce the formation of chromatin loops, thus separating enhancers from promoters of genes. The accumulation of cohesin at CTCF sites is not required for sister chromatid cohesion, as depletion of CTCF does not cause cohesion defects [82]. Thus, CTCF-dependent enrichment of cohesin at defined genomic loci has a specific role in transcription. The mechanism underlying cohesin enrichment at CTCF sites is unclear, but may be a result of a direct interaction between CTCF and the cohesin core subunit SA1/2 [85]. How cohesin is translocated from the original Scc2-Scc4 loading sites to CTCF sites also remains to be addressed. A strong possibility is that the transcriptional machinery actively pushes cohesin rings along chromosomes, as has been postulated in the budding yeast [81], until cohesin encounters CTCF.

\section{Establishment of sister chromatid cohesion}

Fluorescent recovery after photobleaching (FRAP) experiments have shown that cohesin loaded onto DNA in telophase and early G1 turns over rapidly on chromatin in a Wapl-Pds5-dependent manner [8,11]. At least a pool of cohesin interacts with chromatin much more stably after DNA replication [86]. This stably bound cohesin pool is believed to be cohesive and to generate sister chromatid cohesion.

A critical factor required for cohesion establishment is the acetyltransferase Eco1/Ctf7 that acetylates Smc3 [12,14-16,87,88]. In vertebrates, there are two Eco1 orthologs, Esco1 and Esco2, both of which are capable of acetylating Smc3 and contribute to sister chromatid cohesion $[13,16]$. Smc3 acetylation at two conserved lysines is required for cohesion establishment in yeast and in vertebrates, because acetylation mimicking Smc3 mutations bypass the requirement of Eco1 in cohesion [14,16,89]. In yeast, mutations in Wapl, Pds5, and Scc3 bypass the requirement for Ecol and rescue the lethality of ecol mutants $[14,17]$. Thus, acetylation of Smc3 likely counteracts the cohesin-releasing activities of Wapl, Pds5, and Scc3, thereby stabilizing cohesin on chromosomes to establish cohesion. In human cells, sororin is additionally recruited to the acetylated cohesin and further shields cohesin from Wapl [21]. Sororin-bound cohesin is more stably associated with chromatin, and is believed to mediate sister chromatid cohesion. As mentioned previously, sororin homologues have so far only been found in vertebrates and in Drosophila, but not in yeast.

Because the two acetylated lysine residues are located close to the active site of the Smc3 ATPase domain, it has been proposed that Smc3 acetylation blocks the releasing activities by regulating the ATPase activity of cohesin [49]. On the other hand, Esco1-dependent acetylation or the acetylation mimicking mutation of purified recombinant human cohesin does not reduce its ATPase activity [90]. Instead, Smc3 acetylation is strictly dependent on the ATPase activity of cohesin, and is coupled to the loading of cohesin onto DNA by the Scc2-Scc4 complex [90]. Thus, we propose that ATP hydrolysis exposes the two lysines on $\mathrm{Smc} 3$ for acetylation by Esco1/2. Smc3 acetylation directly interferes with the productive interaction between cohesin and Wapl-Pds5, thus stabilizing cohesin on chromatin.

The finding that cohesin acetylation is coupled to its loading suggests that this modification is unlikely to be the sole regulated step in cohesion establishment during $S$ phase. Indeed, cohesin acetylation can occur efficiently before and after DNA replication in Xenopus egg extracts [91]. In human cells, Esco1 has been shown to constitutively co-localize with and mediate the acetylation of cohesin at CTCF sites throughout the cell cycle [65,92]. This replication-independent cohesin acetylation mediates gene silencing [92]. Thus, Smc3 acetylation is necessary but not sufficient for cohesion establishment.

It is possible that only Smc3 acetylation coupled to DNA replication can establish sister chromatid cohesion (Figure 3 ). Consistent with this hypothesis, Eco1 is recruited to the replication fork through an interaction with PCNA in yeast, and the Eco1-PCNA interaction is critical for sister chromatid cohesion [93]. Similarly, the interaction between Esco2 and PCNA is essential for cohesion establishment in Xenopus egg extracts [91]. In addition to PCNA, a large number of proteins with known roles in DNA replication are required for sister chromatid cohesion [94,95]. It remains unclear, however, how cohesion establishment is coupled to DNA replication.

\section{Cohesin release from chromosomes}

Timely dissolution of sister chromatid cohesion in mitosis is critical for accurate chromosome segregation. If cohesion dissolution occurs too early, sister chromatids separate prematurely, and cells undergo spindle checkpoint-dependent arrest in mitosis [27]. If cohesion removal happens too late, incomplete sister chromatid separation leads to lagging chromosomes and aneuploidy in daughter cells. Therefore, cohesive cohesin stably bound to chromatin has to be released in a highly regulated manner. As mentioned previously, cohesin is released from chromosomes in two steps during mitosis in vertebrates (Figure 1). In the first step, Wapl removes the majority of cohesin from 

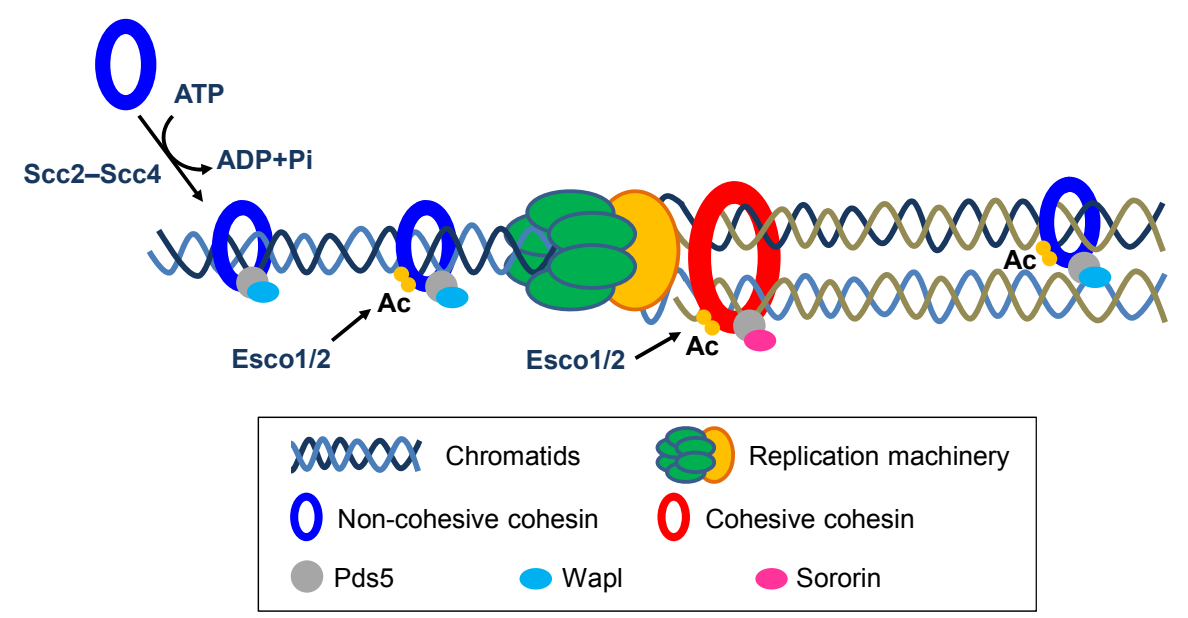

Figure 3 Critical steps involved in cohesion establishment. Cohesin is deposited onto DNA by the Scc2-Scc4 complex and acetylated by Eco1 in yeast and Esco1/2 in human cells. The ATPase activity of cohesin is required in both steps. Cohesin acetylation can occur independently of DNA replication, but only acetylation in association with the replication machinery enables the establishment of sister chromatid cohesion. In metazoans, cohesion establishment also requires the binding of sororin to acetylated cohesin.

chromosome arms in the prophase pathway, but spares a small pool of cohesin at centromeres. In the second step, the centromeric cohesin is cleaved by the protease separase.

When cells entering mitosis, mitotic kinases are activated, and phosphorylate cohesin and its associated regulators [96]. Phosphorylation of SA2 by Plk1 and phosphorylation of sororin by Cdk1 and Aurora B have been shown to be required for efficient cohesin release by Wapl [21,23,24,31,97]. While it is unclear how SA2 phosphorylation stimulates Wapl-dependent release, phosphorylation of sororin disrupts its interaction with Pds5 and cohesin [21]. Sororin dissociation allows Wapl to gain access to Pds5 and to remove cohesin from chromosomes presumably through opening the Smc3-Scc1 interface. The mechanism by which Wapl-Pds5 opens this DNA exit gate of cohesin still remains elusive. It is possible that Wapl-Pds5 stimulates the ATPase activity of cohesin and triggers the opening of the DNA exit gate in a process that requires ATP hydrolysis. Cohesin released in the prophase pathway can be deacetylated by HDAC8 in mammalian cells [98], and deposited onto DNA in the next cell cycle.

By metaphase, only cohesin at centromeres is preserved by the Sgo1-PP2A complex [28,30]. Sgo1 is initially recruited to kinetochores through directly binding to the H2A-pT120 histone mark added by the mitotic kinase Bub1 [34,99,100]. RNA Polymerase II-dependent transcription then drives Sgo1 from kinetochores to centromeres, where it directly binds to cohesin [100]. The Sgo1-cohesin interaction also requires Cdk1-dependent phosphorylation of Sgol and specifically occurs during mitosis [31]. Sgo1 competes with Wapl for binding to a conserved site on SA2-Scc1 and directly shields cohesin from Wapl [32]. In addition, Sgo1 also bridges an interaction between cohesin and PP2A and protects sororin from hyperphosphorylation by mitotic kinase [31]. This preserves the binding of sororin to cohesin and Pds5, which also antagonizes Wapl-dependent cohesin release.

After all sister kinetochores are properly attached to microtubules emanating from the opposite spindle poles and are under tension, the spindle checkpoint is silenced, and the checkpoint target, $\mathrm{APC} / \mathrm{C}$ bound to its mitotic activator $\mathrm{Cdc} 20$ (APC/C $\mathrm{C}^{\mathrm{Cdc20}}$ ), becomes active $[101,102]$. APC/C $\mathrm{C}^{\mathrm{Cdc} 20}$ mediates the ubiquitination of two key separase inhibitors, securin and cyclin B1, resulting in their degradation by the proteasome and leading to separase activation [103,104]. Concurrently, Pol II localization at metaphase kinetochores is also diminished [100]. As a result, Sgol redistributes from centromeres to kinetochores, leaving cohesin at centromeres unprotected. Active separase then cleaves Scc1 at two different sites and releases centromeric cohesin from chromatin, triggering anaphase onset [36]. In yeast, the prophase pathway is not prominent, and most cohesin is cleaved by separase at the metaphase-anaphase transition to enable chromosome segregation [105].

How does separase specifically recognize and cleave chromatin-bound centromeric cohesin while sparing soluble cohesin released in the prophase pathway? Biochemical analysis in vitro showed that separase binds to DNA directly, and cohesin cleavage by separase is stimulated by DNA [106]. This finding provides a possible explanation for why only chromatin-bound cohesin is cleaved by separase, allowing the bulk of cohesin released by Wapl in prophase to remain intact and to be recycled in the next cell cycle. Moreover, a recent study showed that the phosphorylation-dependent peptidyl-prolyl cis/trans isomerase Pin1 catalyzes a conformational change of separase, presumably involving a proline cis/trans isomerization event [107]. In early mitosis, Pin1 is required for cyclin B1-Cdk1- 
dependent inhibition of separase. Pin1-mediated isomerization also limits the half-life of active separase following chromosome segregation in late mitosis. Finally, separase is excluded from the nucleus by nuclear export [108]. In conjunction with securin-dependent inhibition, these regulatory mechanisms fine-tune the proteolytic activity of separase and ensure that active separase cleaves and only cleaves the residual amount of cohesin at centromeres during the metaphase-anaphase transition, but not at other stages of the cell cycle.

\section{Concluding remarks}

Since its discovery two decades ago, much progress has been made toward a molecular understanding of the cohesin complex and its roles in chromosome biology. It has become increasingly clear that intricate spatiotemporal regulation of the establishment and dissolution of sister chromatid cohesion is essential for accurate chromosome segregation. The maintenance of sister chromatid cohesion at centromeres is now well established. On the other hand, many outstanding questions in this field remain to be answered. In particular, the actual mechanics of ATPase-driven loading and release of cohesin to and from chromatin remains to be defined. Reconstitution of these processes with purified components in vitro, coupled with structural and biophysical analysis, will be absolutely necessary for future in-depth mechanistic studies of cohesin.

The authors declare that they have no conflict of interest.

We thank all members of the Yu laboratory for helpful discussions and critical comments. H.Y. is the investigator with the Howard Hughes Medical Institute. This work was supported by the Welch Foundation (I-1441 to H.Y.), the Clayton Foundation, and Cancer Prevention and Research Institute of Texas (RP110465-P3 and RP120717-P2 to H.Y.).

1 Schvartzman JM, Sotillo R, Benezra R. Mitotic chromosomal instability and cancer: mouse modelling of the human disease. Nat Rev Cancer, 2010, 10: 102-115

2 Solomon DA, Kim T, Diaz-Martinez LA, Fair J, Elkahloun AG, Harris BT, Toretsky JA, Rosenberg SA, Shukla N, Ladanyi M, Samuels Y, James CD, Yu H, Kim JS, Waldman T. Mutational inactivation of STAG2 causes aneuploidy in human cancer. Science, 2011, 333: 1039-1043

3 Nasmyth K. Cohesin: a catenase with separate entry and exit gates? Nat Cell Biol, 2011, 13: 1170-1177

4 Haarhuis JH, Elbatsh AM, Rowland BD. Cohesin and its regulation: on the logic of X-shaped chromosomes. Dev Cell, 2014, 31: 7-18

5 Ciosk R, Shirayama M, Shevchenko A, Tanaka T, Toth A, Nasmyth K. Cohesin's binding to chromosomes depends on a separate complex consisting of Scc2 and Scc4 proteins. Mol Cell, 2000, 5: 243-254

6 Tonkin ET, Wang TJ, Lisgo S, Bamshad MJ, Strachan T. NIPBL, encoding a homolog of fungal Scc2-type sister chromatid cohesion proteins and fly Nipped-B, is mutated in Cornelia de Lange syndrome. Nat Genet, 2004, 36: 636-641
7 Watrin E, Schleiffer A, Tanaka K, Eisenhaber F, Nasmyth K, Peters JM. Human Scc4 is required for cohesin binding to chromatin, sister-chromatid cohesion, and mitotic progression. Curr Biol, 2006, 16: $863-874$

8 Kueng S, Hegemann B, Peters BH, Lipp JJ, Schleiffer A, Mechtler K, Peters JM. Wapl controls the dynamic association of cohesin with chromatin. Cell, 2006, 127: 955-967

9 Gandhi R, Gillespie PJ, Hirano T. Human Wapl is a cohesin-binding protein that promotes sister-chromatid resolution in mitotic prophase. Curr Biol, 2006, 16: 2406-2417

10 Sutani T, Kawaguchi T, Kanno R, Itoh T, Shirahige K. Budding yeast Wpl1(Rad61)-Pds5 complex counteracts sister chromatid cohesion-establishing reaction. Curr Biol, 2009, 19: 492-497

11 Chan KL, Roig MB, Hu B, Beckouet F, Metson J, Nasmyth K. Cohesin's DNA exit gate is distinct from its entrance gate and is regulated by acetylation. Cell, 2012, 150: 961-974

12 Ivanov D, Schleiffer A, Eisenhaber F, Mechtler K, Haering CH, Nasmyth K. Eco1 is a novel acetyltransferase that can acetylate proteins involved in cohesion. Curr Biol, 2002, 12: 323-328

13 Hou F, Zou H. Two human orthologues of Eco1/Ctf7 acetyltransferases are both required for proper sister-chromatid cohesion. Mol Biol Cell, 2005, 16: 3908-3918

14 Rolef Ben-Shahar T, Heeger S, Lehane C, East P, Flynn H, Skehel M, Uhlmann F. Ecol-dependent cohesin acetylation during establishment of sister chromatid cohesion. Science, 2008, 321: 563-566

15 Unal E, Heidinger-Pauli JM, Kim W, Guacci V, Onn I, Gygi SP, Koshland DE. A molecular determinant for the establishment of sister chromatid cohesion. Science, 2008, 321: 566-569

16 Zhang J, Shi X, Li Y, Kim BJ, Jia J, Huang Z, Yang T, Fu X, Jung SY, Wang Y, Zhang P, Kim ST, Pan X, Qin J. Acetylation of Smc3 by Eco1 is required for $\mathrm{S}$ phase sister chromatid cohesion in both human and yeast. Mol Cell, 2008, 31: 143-151

17 Rowland BD, Roig MB, Nishino T, Kurze A, Uluocak P, Mishra A, Beckouet F, Underwood P, Metson J, Imre R, Mechtler K, Katis VL, Nasmyth K. Building sister chromatid cohesion: smc3 acetylation counteracts an antiestablishment activity. Mol Cell, 2009, 33: 763-774

18 Rankin S, Ayad NG, Kirschner MW. Sororin, a substrate of the anaphase-promoting complex, is required for sister chromatid cohesion in vertebrates. Mol Cell, 2005, 18: 185-200

19 Schmitz J, Watrin E, Lenart P, Mechtler K, Peters JM. Sororin is required for stable binding of cohesin to chromatin and for sister chromatid cohesion in interphase. Curr Biol, 2007, 17: 630-636

20 Lafont AL, Song J, Rankin S. Sororin cooperates with the acetyltransferase Eco2 to ensure DNA replication-dependent sister chromatid cohesion. Proc Natl Acad Sci USA, 2010, 107: 20364-20369

21 Nishiyama T, Ladurner R, Schmitz J, Kreidl E, Schleiffer A, Bhaskara V, Bando M, Shirahige K, Hyman AA, Mechtler K, Peters JM. Sororin mediates sister chromatid cohesion by antagonizing Wapl. Cell, 2010, 143: 737-749

22 Waizenegger IC, Hauf S, Meinke A, Peters JM. Two distinct pathways remove mammalian cohesin from chromosome arms in prophase and from centromeres in anaphase. Cell, 2000, 103: 399-410

23 Nishiyama T, Sykora MM, Huis In 't Veld PJ, Mechtler K, Peters JM. Aurora B and Cdk1 mediate Wapl activation and release of acetylated cohesin from chromosomes by phosphorylating Sororin. Proc Natl Acad Sci USA, 2013, 110: 13404-13409

24 Dreier MR, Bekier ME, 2nd, Taylor WR. Regulation of sororin by Cdk1-mediated phosphorylation. J Cell Sci, 2011, 124: 2976-2987

25 Zhang N, Panigrahi AK, Mao Q, Pati D. Interaction of sororin protein with polo-like kinase 1 mediates resolution of chromosomal arm cohesion. J Biol Chem, 2011, 286: 41826-41837 
26 Kitajima TS, Kawashima SA, Watanabe Y. The conserved kinetochore protein shugoshin protects centromeric cohesion during meiosis. Nature, 2004, 427: 510-517

27 Tang Z, Sun Y, Harley SE, Zou H, Yu H. Human Bub1 protects centromeric sister-chromatid cohesion through Shugoshin during mitosis. Proc Natl Acad Sci USA, 2004, 101: 18012-18017

28 Kitajima TS, Sakuno T, Ishiguro K, Iemura S, Natsume T, Kawashima SA, Watanabe Y. Shugoshin collaborates with protein phosphatase 2A to protect cohesin. Nature, 2006, 441: 46-52

29 Riedel CG, Katis VL, Katou Y, Mori S, Itoh T, Helmhart W, Galova M, Petronczki M, Gregan J, Cetin B, Mudrak I, Ogris E, Mechtler K, Pelletier L, Buchholz F, Shirahige K, Nasmyth K. Protein phosphatase 2A protects centromeric sister chromatid cohesion during meiosis I. Nature, 2006, 441: 53-61

30 Tang Z, Shu H, Qi W, Mahmood NA, Mumby MC, Yu H. PP2A is required for centromeric localization of $\mathrm{Sgol}$ and proper chromosome segregation. Dev Cell, 2006, 10: 575-585

31 Liu H, Rankin S, Yu H. Phosphorylation-enabled binding of SGO1-PP2A to cohesin protects sororin and centromeric cohesion during mitosis. Nat Cell Biol, 2013, 15: 40-49

32 Hara K, Zheng G, Qu Q, Liu H, Ouyang Z, Chen Z, Tomchick DR, $\mathrm{Yu} H$. Structure of cohesin subcomplex pinpoints direct shugoshin-Wapl antagonism in centromeric cohesion. Nat Struct Mol Biol, 2014, 21: 864-870

33 Lee J, Kitajima TS, Tanno Y, Yoshida K, Morita T, Miyano T, Miyake M, Watanabe Y. Unified mode of centromeric protection by shugoshin in mammalian oocytes and somatic cells. Nat Cell Biol, 2008, 10: 42-52

34 Liu H, Jia L, Yu H. Phospho-H2A and cohesin specify distinct tension-regulated $\mathrm{Sgol}$ pools at kinetochores and inner centromeres. Curr Biol, 2013, 23: 1927-1933

35 Uhlmann F, Wernic D, Poupart MA, Koonin EV, Nasmyth K. Cleavage of cohesin by the $\mathrm{CD}$ clan protease separin triggers anaphase in yeast. Cell, 2000, 103: 375-386

36 Hauf S, Waizenegger IC, Peters JM. Cohesin cleavage by separase required for anaphase and cytokinesis in human cells. Science, 2001, 293: $1320-1323$

37 Remeseiro S, Cuadrado A, Losada A. Cohesin in development and disease. Development, 2013, 140: 3715-3718

$38 \mathrm{Wu} \mathrm{N}, \mathrm{Yu} \mathrm{H}$. The Smc complexes in DNA damage response. Cell Biosci, 2012, 2: 5

39 Musio A, Selicorni A, Focarelli ML, Gervasini C, Milani D, Russo S, Vezzoni P, Larizza L. X-linked Cornelia de Lange syndrome owing to SMC1L1 mutations. Nat Genet, 2006, 38: 528-530

40 Mannini L, Cucco F, Quarantotti V, Krantz ID, Musio A. Mutation spectrum and genotype-phenotype correlation in Cornelia de Lange syndrome. Hum Mutat, 2013, 34: 1589-1596

41 Bose T, Gerton JL. Cohesinopathies, gene expression, and chromatin organization. J Cell Biol, 2010, 189: 201-210

42 Rankin S. Complex elaboration: making sense of meiotic cohesin dynamics. FEBS J, 2015, 282: 2413-2430

43 Guacci V, Koshland D, Strunnikov A. A direct link between sister chromatid cohesion and chromosome condensation revealed through the analysis of MCD1 in S. cerevisiae. Cell, 1997, 91: 47-57

44 Michaelis C, Ciosk R, Nasmyth K. Cohesins: chromosomal proteins that prevent premature separation of sister chromatids. Cell, 1997, 91: 35-45

45 Losada A, Hirano M, Hirano T. Identification of Xenopus SMC protein complexes required for sister chromatid cohesion. Genes Dev, 1998, 12: 1986-1997

46 Sumara I, Vorlaufer E, Gieffers C, Peters BH, Peters JM. Characterization of vertebrate cohesin complexes and their regulation in prophase. J Cell Biol, 2000, 151: 749-762

47 Losada A, Yokochi T, Kobayashi R, Hirano T. Identification and characterization of $\mathrm{SA} / \mathrm{Scc} 3 \mathrm{p}$ subunits in the Xenopus and human cohesin complexes. J Cell Biol, 2000, 150: 405-416

48 Hirano T. At the heart of the chromosome: SMC proteins in action. Nat Rev Mol Cell Biol, 2006, 7: 311-322

49 Gligoris TG, Scheinost JC, Burmann F, Petela N, Chan KL, Uluocak P, Beckouet F, Gruber S, Nasmyth K, Lowe J. Closing the cohesin ring: structure and function of its Smc3-kleisin interface. Science, 2014, 346: 963-967

50 Huis in 't Veld PJ, Herzog F, Ladurner R, Davidson IF, Piric S, Kreidl E, Bhaskara V, Aebersold R, Peters JM. Characterization of a DNA exit gate in the human cohesin ring. Science, 2014, 346: 968-972

51 Haering CH, Schoffnegger D, Nishino T, Helmhart W, Nasmyth K, Lowe J. Structure and stability of cohesin's Smc1-kleisin interaction. Mol Cell, 2004, 15: 951-964

52 Roig MB, Lowe J, Chan KL, Beckouet F, Metson J, Nasmyth K. Structure and function of cohesin's Scc3/SA regulatory subunit. FEBS Lett, 2014, 588: 3692-3702

53 Ivanov D, Nasmyth K. A topological interaction between cohesin rings and a circular minichromosome. Cell, 2005, 122: 849-860

54 Haering CH, Farcas AM, Arumugam P, Metson J, Nasmyth K. The cohesin ring concatenates sister DNA molecules. Nature, 2008, 454: 297-301

55 Gruber S, Arumugam P, Katou Y, Kuglitsch D, Helmhart W, Shirahige K, Nasmyth K. Evidence that loading of cohesin onto chromosomes involves opening of its SMC hinge. Cell, 2006, 127: 523-537

56 Buheitel J, Stemmann O. Prophase pathway-dependent removal of cohesin from human chromosomes requires opening of the Smc3-Scc1 gate. EMBO J, 2013, 32: 666-676

57 Hartman T, Stead K, Koshland D, Guacci V. Pds5p is an essential chromosomal protein required for both sister chromatid cohesion and condensation in Saccharomyces cerevisiae. J Cell Biol, 2000, 151: 613-626

58 Panizza S, Tanaka T, Hochwagen A, Eisenhaber F, Nasmyth K. Pds5 cooperates with cohesin in maintaining sister chromatid cohesion. Curr Biol, 2000, 10: 1557-1564

59 Losada A, Yokochi T, Hirano T. Functional contribution of Pds5 to cohesin-mediated cohesion in human cells and Xenopus egg extracts. J Cell Sci, 2005, 118: 2133-2141

60 Chan KL, Gligoris T, Upcher W, Kato Y, Shirahige K, Nasmyth K, Beckouet F. Pds5 promotes and protects cohesin acetylation. Proc Natl Acad Sci USA, 2013, 110: 13020-13025

61 Tanaka K, Hao Z, Kai M, Okayama H. Establishment and maintenance of sister chromatid cohesion in fission yeast by a unique mechanism. EMBO J, 2001, 20: 5779-5790

62 Shintomi K, Hirano T. Releasing cohesin from chromosome arms in early mitosis: opposing actions of Wapl-Pds5 and Sgo1. Genes Dev, 2009, 23: 2224-2236

63 Carretero M, Ruiz-Torres M, Rodriguez-Corsino M, Barthelemy I, Losada A. Pds5B is required for cohesion establishment and Aurora B accumulation at centromeres. EMBO J, 2013, 32: 2938-2949

64 Zhang B, Jain S, Song H, Fu M, Heuckeroth RO, Erlich JM, Jay PY, Milbrandt J. Mice lacking sister chromatid cohesion protein PDS5B exhibit developmental abnormalities reminiscent of Cornelia de Lange syndrome. Development, 2007, 134: 3191-3201

65 Minamino M, Ishibashi M, Nakato R, Akiyama K, Tanaka H, Kato Y, Negishi L, Hirota T, Sutani T, Bando M, Shirahige K. Esco1 Acetylates Cohesin via a Mechanism Different from That of Esco2. Curr Biol, 2015, 25: 1694-1706

66 Verni F, Gandhi R, Goldberg ML, Gatti M. Genetic and molecular analysis of wings apart-like (wapl), a gene controlling heterochromatin organization in Drosophila melanogaster. Genetics, 2000, 154: 1693-1710

67 Chatterjee A, Zakian S, Hu XW, Singleton MR. Structural insights into the regulation of cohesion establishment by Wpl1. EMBO J, 
2013, 32: 677-687

68 Ouyang Z, Zheng G, Song J, Borek DM, Otwinowski Z, Brautigam CA, Tomchick DR, Rankin S, Yu H. Structure of the human cohesin inhibitor Wapl. Proc Natl Acad Sci USA, 2013, 110: 11355-11360

69 Tedeschi A, Wutz G, Huet S, Jaritz M, Wuensche A, Schirghuber E, Davidson IF, Tang W, Cisneros DA, Bhaskara V, Nishiyama T, Vaziri A, Wutz A, Ellenberg J, Peters JM. Wapl is an essential regulator of chromatin structure and chromosome segregation. Nature, 2013, 501: 564-568

70 Haarhuis JH, Elbatsh AM, van den Broek B, Camps D, Erkan H, Jalink K, Medema RH, Rowland BD. WAPL-mediated removal of cohesin protects against segregation errors and aneuploidy. Curr Biol, 2013, 23: 2071-2077

71 Krantz ID, McCallum J, DeScipio C, Kaur M, Gillis LA, Yaeger D, Jukofsky L, Wasserman N, Bottani A, Morris CA, Nowaczyk MJ, Toriello H, Bamshad MJ, Carey JC, Rappaport E, Kawauchi S, Lander AD, Calof AL, Li HH, Devoto M, Jackson LG. Cornelia de Lange syndrome is caused by mutations in NIPBL, the human homolog of Drosophila melanogaster Nipped-B. Nat Genet, 2004, 36: 631-635

72 Neuwald AF, Hirano T. HEAT repeats associated with condensins, cohesins, and other complexes involved in chromosome-related functions. Genome Res, 2000, 10: 1445-1452

73 Hinshaw SM, Makrantoni V, Kerr A, Marston AL, Harrison SC. Structural evidence for Scc4-dependent localization of cohesin loading. eLife, 2015, 4: e06057

74 Chao WC, Murayama Y, Munoz S, Costa A, Uhlmann F, Singleton MR. Structural Studies Reveal the Functional Modularity of the Scc2-Scc4 Cohesin Loader. Cell Rep, 2015, 12: 719-725

75 Murayama Y, Uhlmann F. Biochemical reconstitution of topological DNA binding by the cohesin ring. Nature, 2014, 505: 367-371

76 Kagey MH, Newman JJ, Bilodeau S, Zhan Y, Orlando DA, van Berkum NL, Ebmeier CC, Goossens J, Rahl PB, Levine SS, Taatjes DJ, Dekker J, Young RA. Mediator and cohesin connect gene expression and chromatin architecture. Nature, 2010, 467: 430-435

77 Huang J, Hsu JM, Laurent BC. The RSC nucleosome-remodeling complex is required for Cohesin's association with chromosome arms. Mol Cell, 2004, 13: 739-750

78 Gillespie PJ, Hirano T. Scc2 couples replication licensing to sister chromatid cohesion in Xenopus egg extracts. Curr Biol, 2004, 14: 1598-1603

79 Takahashi TS, Yiu P, Chou MF, Gygi S, Walter JC. Recruitment of Xenopus Scc2 and cohesin to chromatin requires the pre-replication complex. Nat Cell Biol, 2004, 6: 991-996

80 Takahashi TS, Basu A, Bermudez V, Hurwitz J, Walter JC. Cdc7-Drf1 kinase links chromosome cohesion to the initiation of DNA replication in Xenopus egg extracts. Genes Dev, 2008, 22: 1894-1905

81 Lengronne A, Katou Y, Mori S, Yokobayashi S, Kelly GP, Itoh T, Watanabe Y, Shirahige K, Uhlmann F. Cohesin relocation from sites of chromosomal loading to places of convergent transcription. Nature, 2004, 430: 573-578

82 Wendt KS, Yoshida K, Itoh T, Bando M, Koch B, Schirghuber E, Tsutsumi S, Nagae G, Ishihara K, Mishiro T, Yahata K, Imamoto F, Aburatani H, Nakao M, Imamoto N, Maeshima K, Shirahige K, Peters JM. Cohesin mediates transcriptional insulation by CCCTC-binding factor. Nature, 2008, 451: 796-801

83 Rubio ED, Reiss DJ, Welcsh PL, Disteche CM, Filippova GN, Baliga NS, Aebersold R, Ranish JA, Krumm A. CTCF physically links cohesin to chromatin. Proc Natl Acad Sci USA, 2008, 105: 8309-8314

84 Merkenschlager M, Odom DT. CTCF and cohesin: linking gene regulatory elements with their targets. Cell, 2013, 152: 1285-1297

85 Xiao T, Wallace J, Felsenfeld G. Specific sites in the C terminus of CTCF interact with the SA2 subunit of the cohesin complex and are required for cohesin-dependent insulation activity. Mol Cell Biol, 2011, 31: 2174-2183

86 Gerlich D, Koch B, Dupeux F, Peters JM, Ellenberg J. Live-cell imaging reveals a stable cohesin-chromatin interaction after but not before DNA replication. Curr Biol, 2006, 16: 1571-1578

87 Skibbens RV, Corson LB, Koshland D, Hieter P. Ctf7p is essential for sister chromatid cohesion and links mitotic chromosome structure to the DNA replication machinery. Genes Dev, 1999, 13: 307-319

88 Toth A, Ciosk R, Uhlmann F, Galova M, Schleiffer A, Nasmyth K. Yeast cohesin complex requires a conserved protein, Eco1p(Ctf7), to establish cohesion between sister chromatids during DNA replication. Genes Dev, 1999, 13: 320-333

89 Wu N, Kong X, Ji Z, Zeng W, Potts PR, Yokomori K, Yu H. Scc1 sumoylation by Mms21 promotes sister chromatid recombination through counteracting Wapl. Genes Dev, 2012, 26: 1473-1485

90 Ladurner R, Bhaskara V, Huis in 't Veld PJ, Davidson IF, Kreidl E, Petzold G, Peters JM. Cohesin's ATPase activity couples cohesin loading onto DNA with Smc3 acetylation. Curr Biol, 2014, 24: 2228-2237

91 Song J, Lafont A, Chen J, Wu FM, Shirahige K, Rankin S. Cohesin acetylation promotes sister chromatid cohesion only in association with the replication machinery. J Biol Chem, 2012, 287: 34325-34336

92 Rahman S, Jones MJ, Jallepalli PV. Cohesin recruits the Esco1 acetyltransferase genome wide to repress transcription and promote cohesion in somatic cells. Proc Natl Acad Sci U S A, 2015, 10.1073/pnas.1505323112

93 Moldovan GL, Pfander B, Jentsch S. PCNA controls establishment of sister chromatid cohesion during S phase. Mol Cell, 2006, 23: 723-732

94 Sherwood R, Takahashi TS, Jallepalli PV. Sister acts: coordinating DNA replication and cohesion establishment. Genes Dev, 2010, 24 : 2723-2731

95 Borges V, Smith DJ, Whitehouse I, Uhlmann F. An Eco1independent sister chromatid cohesion establishment pathway in $\mathrm{S}$. cerevisiae. Chromosoma, 2013, 122: 121-134

96 Hegemann B, Hutchins JR, Hudecz O, Novatchkova M, Rameseder J, Sykora MM, Liu S, Mazanek M, Lenart P, Heriche JK, Poser I, Kraut N, Hyman AA, Yaffe MB, Mechtler K, Peters JM. Systematic phosphorylation analysis of human mitotic protein complexes. Sci Signal, 2011, 4: rs12

97 Hauf S, Roitinger E, Koch B, Dittrich CM, Mechtler K, Peters JM. Dissociation of cohesin from chromosome arms and loss of arm cohesion during early mitosis depends on phosphorylation of SA2. PLoS Biol, 2005, 3: e69

98 Deardorff MA, Bando M, Nakato R, Watrin E, Itoh T, Minamino M, Saitoh K, Komata M, Katou Y, Clark D, Cole KE, De Baere E, Decroos C, Di Donato N, Ernst S, Francey LJ, Gyftodimou Y, Hirashima K, Hullings M, Ishikawa Y, Jaulin C, Kaur M, Kiyono T, Lombardi PM, Magnaghi-Jaulin L, Mortier GR, Nozaki N, Petersen MB, Seimiya H, Siu VM, Suzuki Y, Takagaki K, Wilde JJ, Willems PJ, Prigent C, Gillessen-Kaesbach G, Christianson DW, Kaiser FJ, Jackson LG, Hirota T, Krantz ID, Shirahige K. HDAC8 mutations in Cornelia de Lange syndrome affect the cohesin acetylation cycle. Nature, 2012, 489: 313-317

99 Kawashima SA, Yamagishi Y, Honda T, Ishiguro K, Watanabe Y. Phosphorylation of $\mathrm{H} 2 \mathrm{~A}$ by Bub1 prevents chromosomal instability through localizing shugoshin. Science, 2010, 327: 172-177

100 Liu H, Qu Q, Warrington R, Rice A, Cheng N, Yu H. Mitotic Transcription Installs Sgol at Centromeres to Coordinate Chromosome Segregation. Mol Cell, 2015, 59: 426-436

101 Jia L, Kim S, Yu H. Tracking spindle checkpoint signals from kinetochores to APC/C. Trends in biochemical sciences, 2013, 38: 302-311

102 London N, Biggins S. Signalling dynamics in the spindle checkpoint response. Nat Rev Mol Cell Biol, 2014, 15: 736-747 
103 Zou H, McGarry TJ, Bernal T, Kirschner MW. Identification of a vertebrate sister-chromatid separation inhibitor involved in transformation and tumorigenesis. Science, 1999, 285: 418-422

104 Stemmann O, Zou H, Gerber SA, Gygi SP, Kirschner MW. Dual inhibition of sister chromatid separation at metaphase. Cell, 2001, 107: 715-726

105 Uhlmann F, Lottspeich F, Nasmyth K. Sister-chromatid separation at anaphase onset is promoted by cleavage of the cohesin subunit Scc1. Nature, 1999, 400: 37-42
106 Sun Y, Kucej M, Fan HY, Yu H, Sun QY, Zou H. Separase is recruited to mitotic chromosomes to dissolve sister chromatid cohesion in a DNA-dependent manner. Cell, 2009, 137: 123-132

107 Hellmuth S, Rata S, Brown A, Heidmann S, Novak B, Stemmann O. Human chromosome segregation involves multi-layered regulation of separase by the peptidyl-prolyl-isomerase Pin1. Mol Cell, 2015, 58: 495-506

108 Sun Y, Yu H, Zou H. Nuclear exclusion of separase prevents cohesin cleavage in interphase cells. Cell Cycle, 2006, 5: 2537-2542

\section{Biographical Sketch}

Yu HongTao, is Professor of Pharmacology at the University of Texas (UT) Southwestern Medical Center at Dallas and Investigator at the Howard Hughes Medical Institute (HHMI). Dr. Yu was born in China in 1969. He received his B.S. in

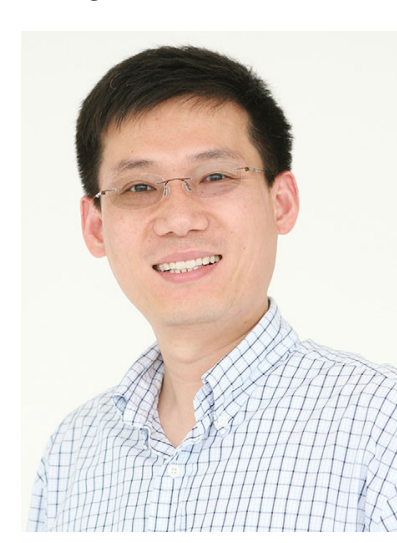
Chemistry from Peking University (Beijing, China) in 1990. He went to the United States to pursue his graduate studies, and received his Ph.D. in Chemistry from Harvard University (Cambridge, MA) in 1995. His thesis research with Dr. Stuart Schreiber focused on the structure determination of protein modules in signal transduction by nuclear magnetic resonance (NMR) spectroscopy. He then completed his postdoctoral training (1995-1999) with Dr. Marc Kirschner at Harvard Medical School. During his postdoctoral training, Dr. Yu studied the composition, function, and regulation of the anaphase-promoting complex or cyclosome (APC/C), a multisubunit ubiquitin ligase critical for cell cycle progression. Dr. Yu began his independent research career in 1999 in the Department of Pharmacology at UT Southwestern Medical Center, and was promoted to Associate Professor with tenure in 2004 and to Professor in 2008. He was selected as an HHMI Investigator in 2008, and was elected a Fellow of the American Association for the Advancement of Science (AAAS) in 2012. Using a multidisciplinary approach, his lab has contributed significantly to the molecular mechanisms of chromosome segregation and genome maintenance.

Open Access This article is distributed under the terms of the Creative Commons Attribution License which permits any use, distribution, and reproduction in any medium, provided the original author(s) and source are credited. 